Full length article

\title{
Validation of IgY for the diagnosis of Streptococcus agalactiae-caused endocarditis and bacterial meningitis in Nile tilapia (Oreochromis niloticus)
}

\author{
Silas F. Eto ${ }^{a, *}$, Dayanne C. Fernandes ${ }^{\mathrm{a}, \mathrm{b}}$, Alessandra C. Moraes ${ }^{\mathrm{c}}$, Ed Johnny R. Prado ${ }^{\mathrm{c}}$, \\ Amanda C. Baldassi $^{\mathrm{a}}$, Wilson G. Manrique ${ }^{\mathrm{d}}$, Ives C. Silva ${ }^{\mathrm{c}}$, Andrea S.R. Medeiros ${ }^{\mathrm{c}}$, \\ Marco A.A. Belo ${ }^{c}$, Tiago S. Balbuena ${ }^{a}$, Samir I. Samara ${ }^{c}$, João M. Pizauro ${ }^{a, b}$ \\ ${ }^{a}$ Department of Technology, School of Agrarian and Veterinary Sciences, Sao Paulo State University (Unesp), Via Prof. Paulo Donato Castellane, km 05, Jaboticabal, Sao \\ Paulo, Brazil \\ ${ }^{\mathrm{b}}$ Institute of Chemistry of Unesp, Sao Paulo, Brazil \\ ${ }^{\mathrm{c}}$ Department of Preventive Veterinary Medicine of Unesp, Sao Paulo, Brazi \\ ${ }^{\mathrm{d}}$ Laboratory of Animal Pathology, Rondônia Federal University, Brazil
}

\section{A R T I C L E I N F O}

\section{Keywords:}

Immunodiagnostics

Antibody

Teleost fish

Neuropathy

\begin{abstract}
A B S T R A C T
Streptococcus agalactiae (Sta), which belongs to Lancefield group B, causes sepsis, endocarditis and bacterial meningitis in human neonates and Nile tilapia. Because the pathophysiology of Sta infection is partially similar in both species, the identification of biomarkers for the diagnosis and study of this disease is of importance for human and animal health. Therefore, in the present study, we produced an immunoglobulin Y (IgY) by immunizing laying hens with Sta proteins and evaluated its ability to detect Sta in paraffinized tilapia brain and cardiac tissue by direct immunofluorescence (IMF) and indirect immunohistochemistry (IHC). The IgY produced was effective in the diagnosis of Sta infection in Nile tilapia, justifying the use of this species as a biomodel for the study of this disease.
\end{abstract}

\section{Introduction}

Streptococcus agalactiae (Sta) is a Gram-positive bacterium that is cosmopolitan and commensal and has the ability to infect a wide variety of species, including fish, reptiles, amphibians, birds, mammals and humans [1]. To date, it has been classified into nine serotypes: Ia, Ib and II-IX [2]. Serotypes Ia, Ib and III and serotypes Ia, III and IV are associated with infection in Nile tilapia and humans, respectively [3]. In humans, it has etiological prevalence in neonatal bacterial meningitis and adult endocarditis and pneumonia [4].

In the Nile tilapia, Sta colonizes cardiac tissue, injuring cardiac fibers and central nervous tissue, and causes suppurative meningitis, resulting in severe sequelae in the host [5]. The migration of Sta from systemic circulation to the central nervous system (CNS) is related to the virulence factors expressed by the pathogen, such as the polysaccharide capsule, pili, serine-rich (SR) proteins, $\beta$-hemolysin, cytolysin, fibronectin and teichoic acid [6]. All these factors contribute to the intracellular survival of Sta and its use of phagocytes to cross the blood-brain barrier (BBB) and migrate to the CNS, which is referred to as a "Trojan horse" from a Greek literary epic [7].

In addition to the similarity between tilapia and human Sta infection mechanisms, an important serotype III-4 variant isolated from aquatic organisms was associated with emergent infections in humans in Asia, indicating the zoonotic potential of this bacterium and its impact in the health sector [8]. These findings highlight the importance of this pathogen in veterinary and human medicine, as well as its direct impact on the global economy, through losses in the aquaculture sector.

The efficacy of immunoglobulin Y (IgY), extracted from the egg yolk of laying hens, in the diagnosis and treatment of microbial infections in aquatic organisms has been demonstrated for Vibrio anguillarum in Cynoglossus semilaevis [9], Vibrio alginolyticus in Haliotis sp. [10]. and for the treatment of shrimp White Spot Syndrome Virus [11]. Therefore, the present study produced an anti-Sta IgY and validated its application for the diagnosis of endocarditis and bacterial meningitis in tilapia, indicating that this species could be a model for this disease.

\section{Materials and methods}

\subsection{Bacteria and separation of bacterial proteins}

Sta was isolated from naturally infected fish and identified by PCR following the method described by Berridgea et al. [12] and El-Razika

\footnotetext{
* Corresponding author.

E-mail address: silasetoigy@gmail.com (S.F. Eto)
} 


\section{$\mathbf{a}$}
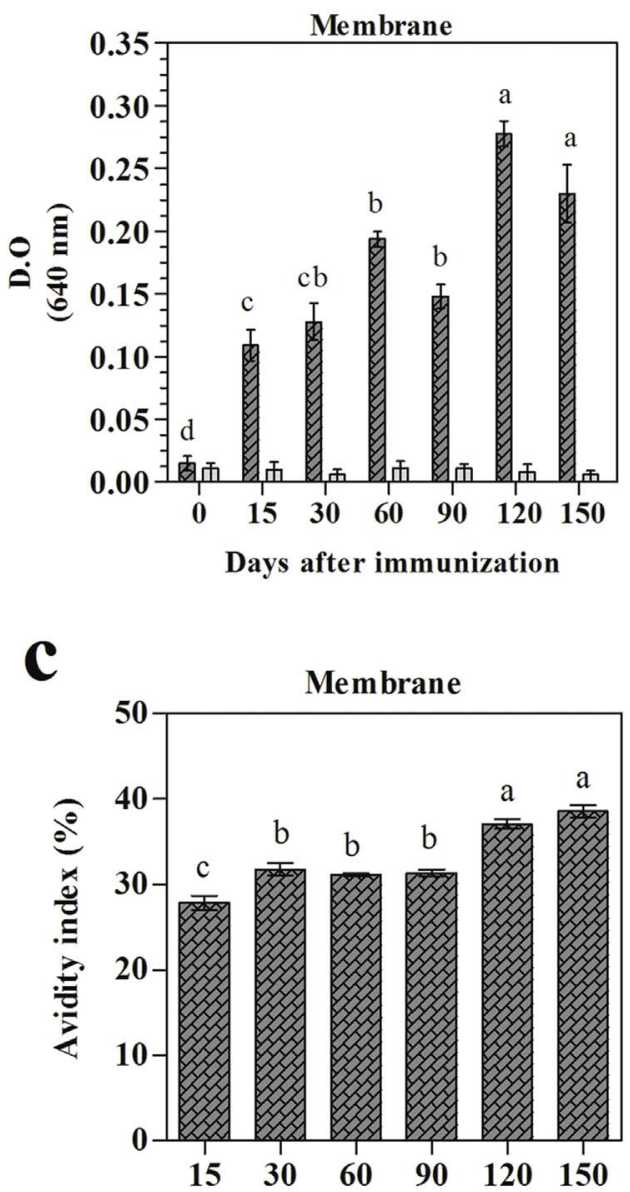

Days after immunization

\section{b}

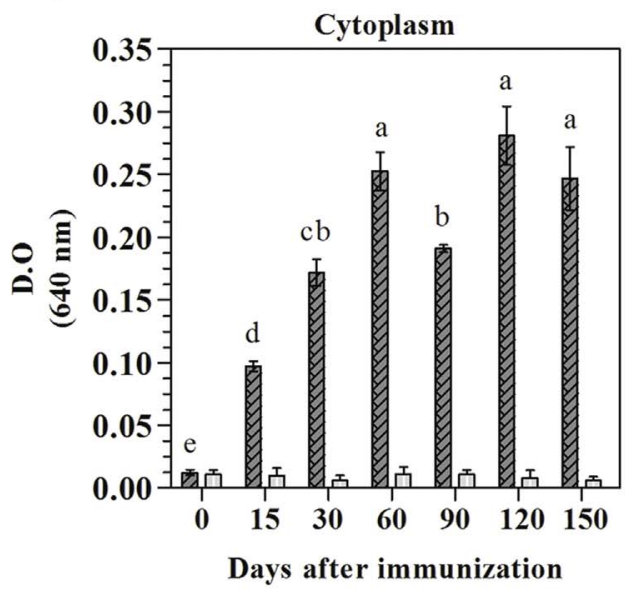

d

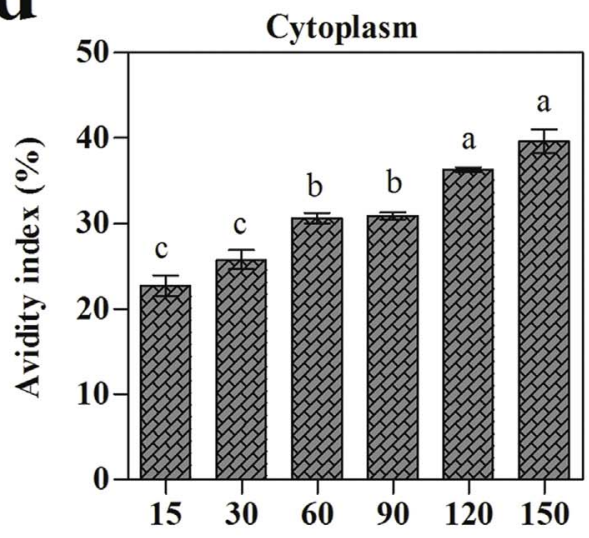

Days after immunization

एक्य Specific IgY $\square$ Nonspecific IgY

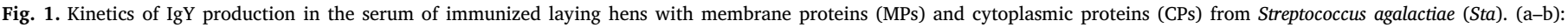

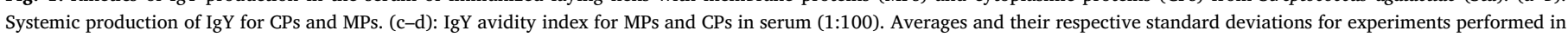
triplicate are presented, and different letters indicate significant differences (Tukey's test, $\mathrm{p}<0.05$ ) between the observed times.

et al. [13]. The protein separantion method followed the protocol described by Sayuri et al. [14]. Sta was cultured in BHI broth (Difco, Detroit, MI, USA) at $28^{\circ} \mathrm{C}$ with shaking for $48 \mathrm{~h}$. The culture medium was removed by centrifugation at $10,000 \mathrm{~g}$ for $10 \mathrm{~min}$ at $4{ }^{\circ} \mathrm{C}$, and the cell pellet was washed four times with $0.15 \mathrm{M}$ PBS, $\mathrm{pH}$ 7.2. Subsequently, the pellet was resuspended in $25 \mathrm{mM}$ Tris- $\mathrm{HCl}, \mathrm{pH} 7.4$, and the cells were lysed in a Sonifier 250 ultrasonic sonicator (Branson Ultrasonics, Danbury, CT, USA). The sample was centrifuged at $2000 \mathrm{~g}$ at $4{ }^{\circ} \mathrm{C}$ for $10 \mathrm{~min}$ to precipitate intact cells. The supernatant was then filtered through a $0.22-\mu \mathrm{m}$ filter and centrifuged at $100,000 \mathrm{~g}$ for $2 \mathrm{~h}$ at $4{ }^{\circ} \mathrm{C}$, and the supernatant containing cytoplasmic proteins (CPs) was collected. The precipitated membrane proteins (MPs) were resuspended

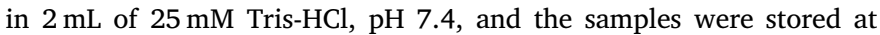
$-70^{\circ} \mathrm{C}$.

\subsection{Hens immunization}

Fourteen 16-week-old hens from the Isa Brown lineage were randomly assigned to two groups $(\mathrm{n}=7)$ : control (non-specific $\mathrm{IgY})$ and experimental (specific IgY). Hens were maintained in individual cages with $12 \mathrm{~h}$ of light and $12 \mathrm{~h}$ of darkness, an ambient temperature between $26^{\circ} \mathrm{C}$ and $29^{\circ} \mathrm{C}$, a relative humidity of $63 \%-75 \%$, drinking water ad libitum and commercial stall feed $(100 \mathrm{~g} / \mathrm{bird} /$ day $)$. The experimental group received three doses of the total extract containing the two protein fractions from Sta MPs and CPs at a final concentration of $200 \mu \mathrm{g} / \mathrm{mL}$ emulsified with incomplete Freud's adjuvant (Sigma-Aldrich Corp., St. Louis, MO, USA) at 30-day intervals, injected at four distinct points on the pectoral muscle. The control group was injected with $0.15 \mathrm{M}$ PBS, pH 7.2. Serum was collected prior to immunization and at $15,30,60,90,120$ and 150 days after the initiation of the protocol.

\subsection{Enzyme linked immunosorbent assay (ELISA)}

\subsubsection{Monitoring systemic production of specific IgY}

The ELISA method followed the protocol described by Tong et al. [15]. A flat-bottom 96-well plate (Costar; Sigma-Aldrich Corp., St. Louis, MO, USA) was sensitized with a $100 \mu \mathrm{l} /$ well volume of $10 \mu \mathrm{g} / \mathrm{mL}$ MPs and CPs and incubated overnight in a wet chamber at $4{ }^{\circ} \mathrm{C}$. It was then washed with PBS-Tween and blocked with $250 \mu$ of PBS containing 5\% Molico skim milk (Nestlé Brazil, São Paulo, Brazil) for $1 \mathrm{~h}$ at room temperature. Subsequently, the serum was diluted (1:1000 v/v) in $1 \%$ PBS-milk, distributed, incubated for $1 \mathrm{~h}$, and washed with $0.05 \%$ PBS-Tween. Additionally, $100 \mu \mathrm{l} /$ well of anti-IgY peroxidase (Bethyl Laboratories, Inc., Montgomery, TX, USA) diluted 1:1000 in PBS was 


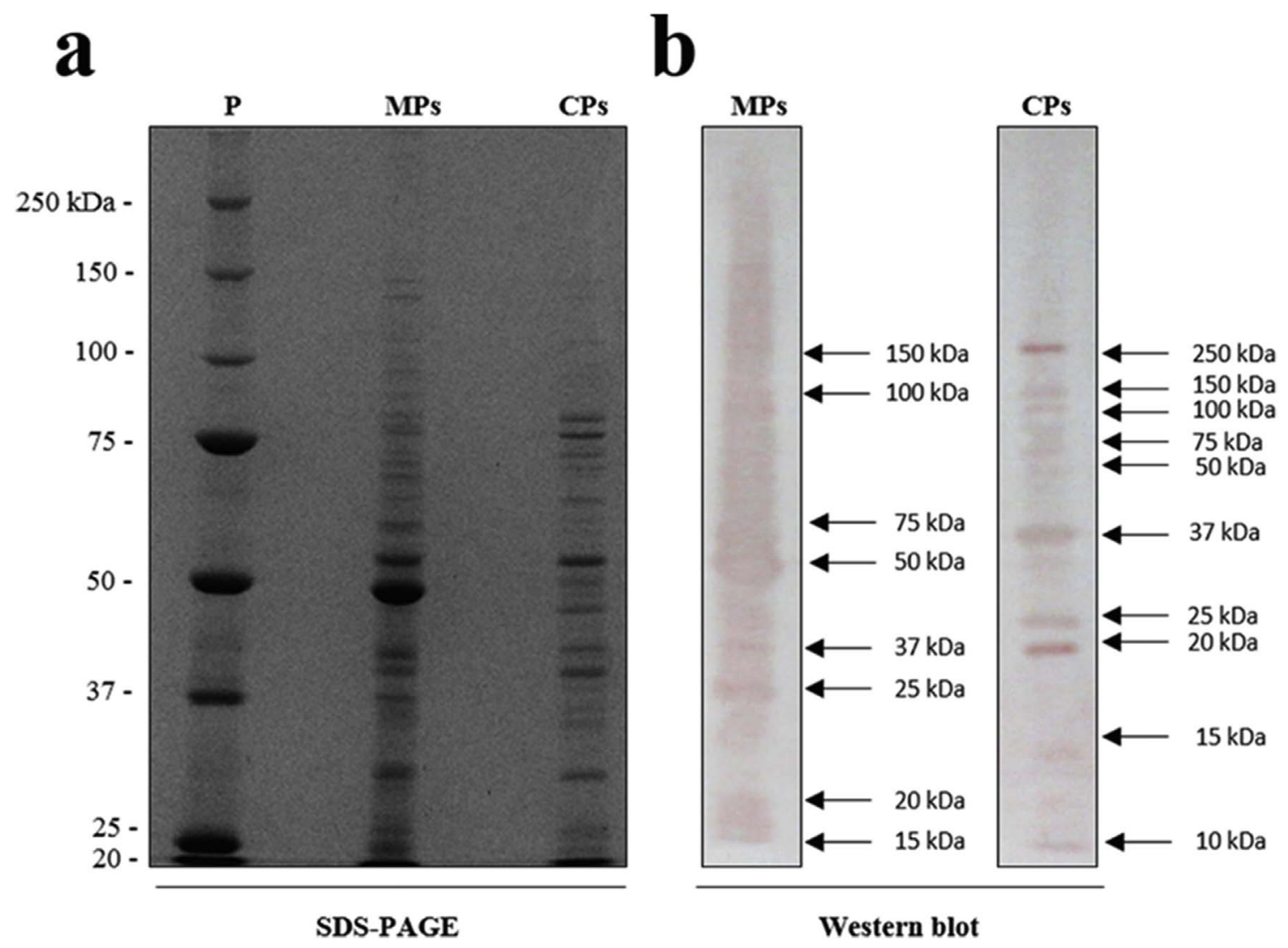

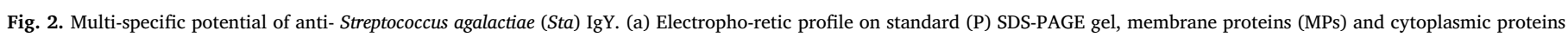
(CPs) of Sta. (b) Western blot using the serum of laying hens immunized with total proteins of Sta (1:100).
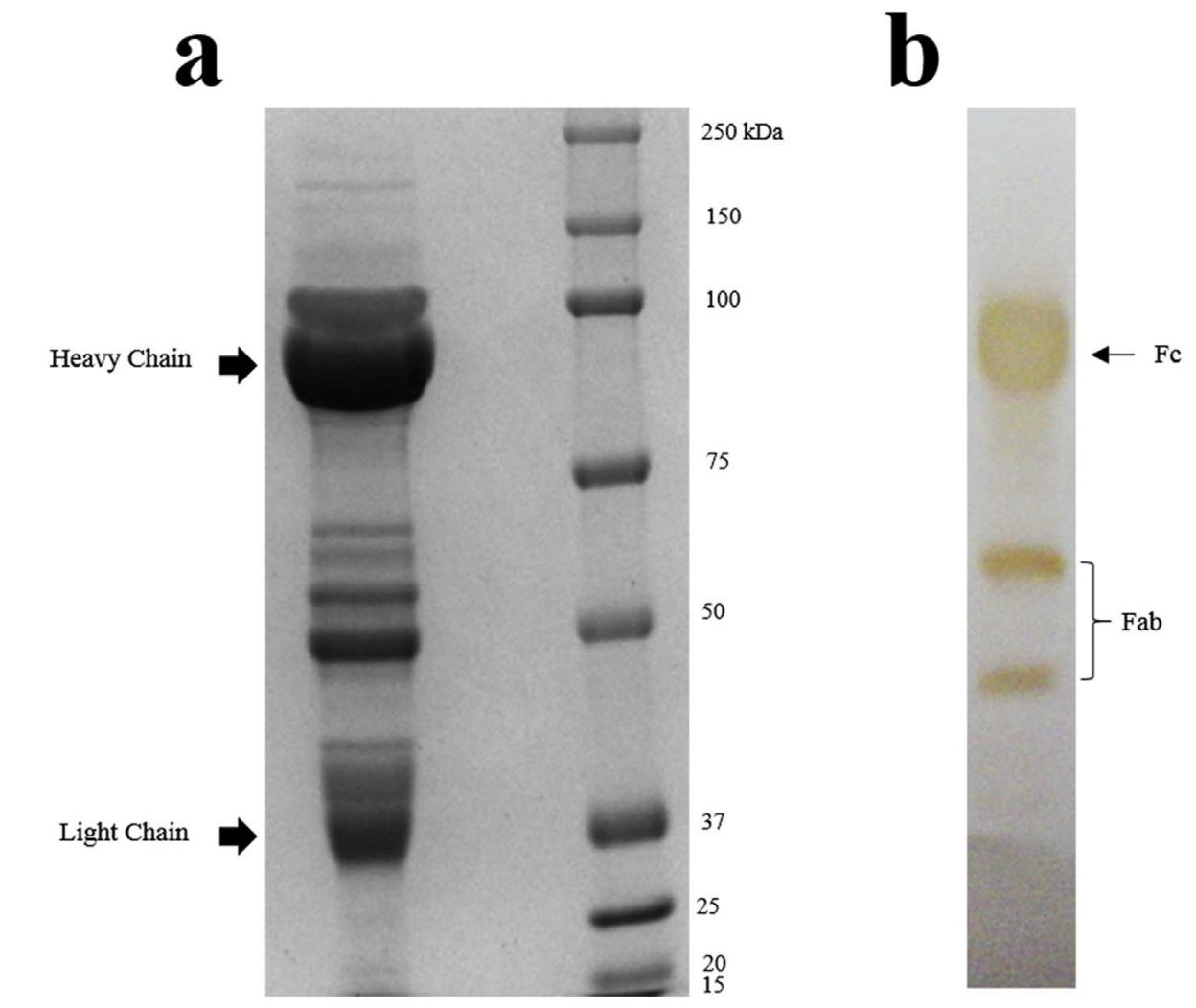

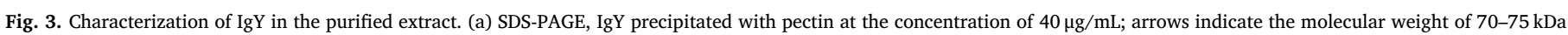
(IgY heavy chain) and 20-25 kDa (IgY light chain). (b) Western blot-positive immunoblotting for IgY fractions. PM: molecular standard. 


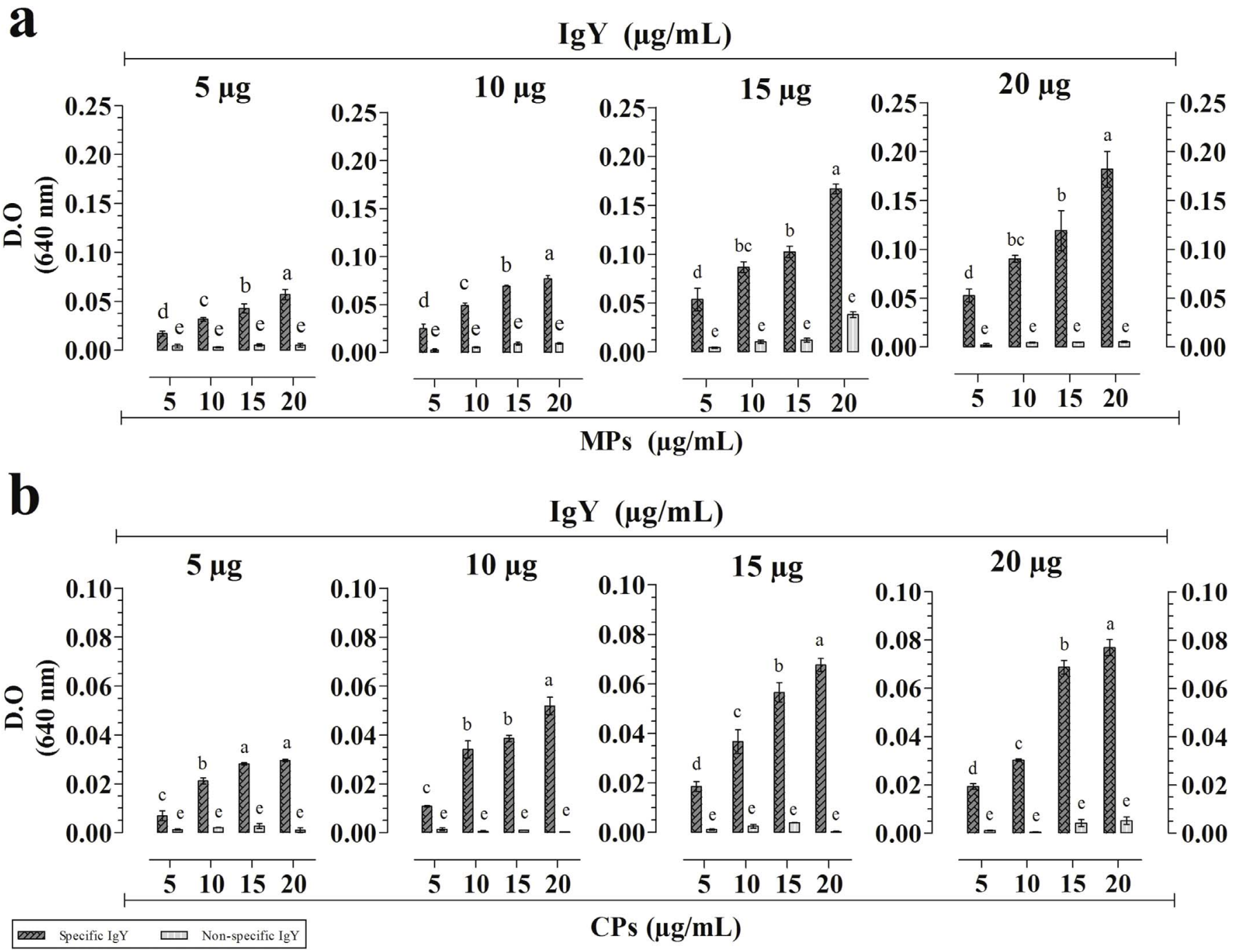

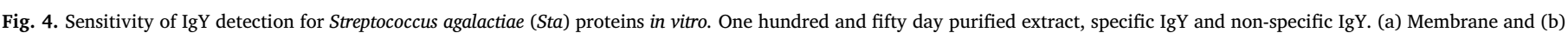

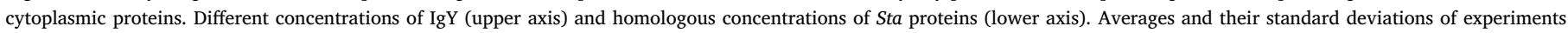
performed in triplicate are presented. Different letters indicate significant differences by Tukey's test $(\mathrm{p}<0.05)$.
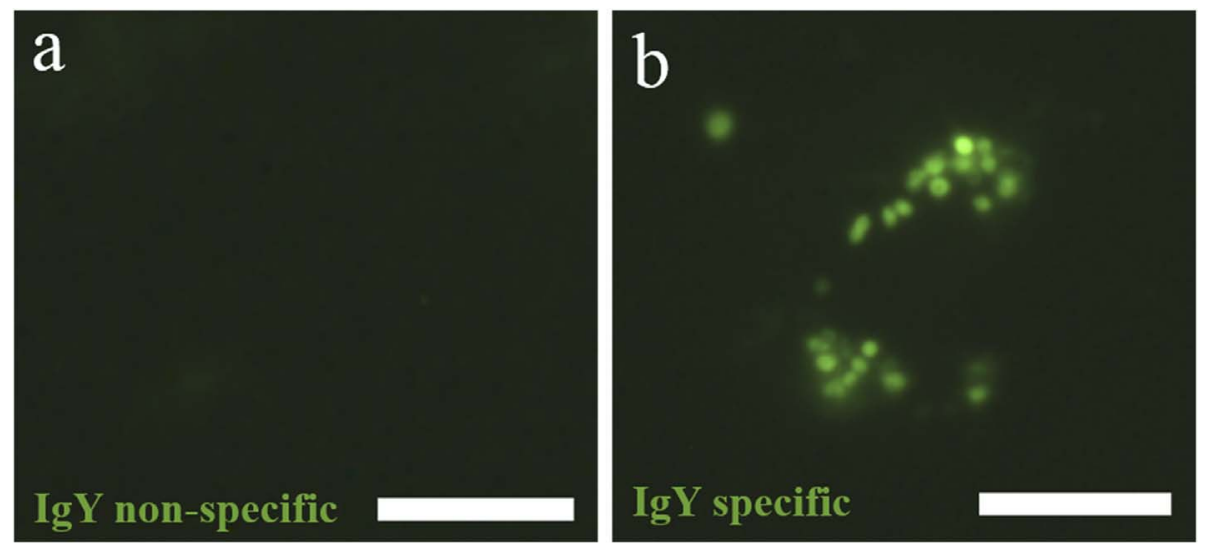

Fig. 5. Detection of Streptococcus agalactiae (Sta) cells with anti-Sta IgY conjugated to fluorescein isothiocyanate (FITC); (a) non-specific IgY and (b) specific IgY. Bar: $10 \mu \mathrm{m}$.

added, and the mixture was incubated for $1 \mathrm{~h}$. It was then washed, and the substrate $\left(\mathrm{H}_{2} \mathrm{O}_{2} / \mathrm{ABST}\right)$ was added; the reaction was quenched with a $5 \%$ SDS solution. The absorbance was determined at $640 \mathrm{~nm}$ on a microplate reader (Molecular Devices SpectraMax, Molecular Devices, Sunnyvale, CA, USA).

\subsection{2. $\operatorname{Ig} Y$ affinity}

After incubation of the serum as described in the previous section, the wells were washed with PBS-Tween. A $1 \mathrm{M}$ urea solution was added to a final volume of $100 \mu \mathrm{L} /$ well (in triplicate). Saline solution $(0.9 \%$ $\mathrm{NaCl}$ ) was used for the control samples, and the reaction was incubated for $30 \mathrm{~min}$ at room temperature. The wells were washed and incubated 

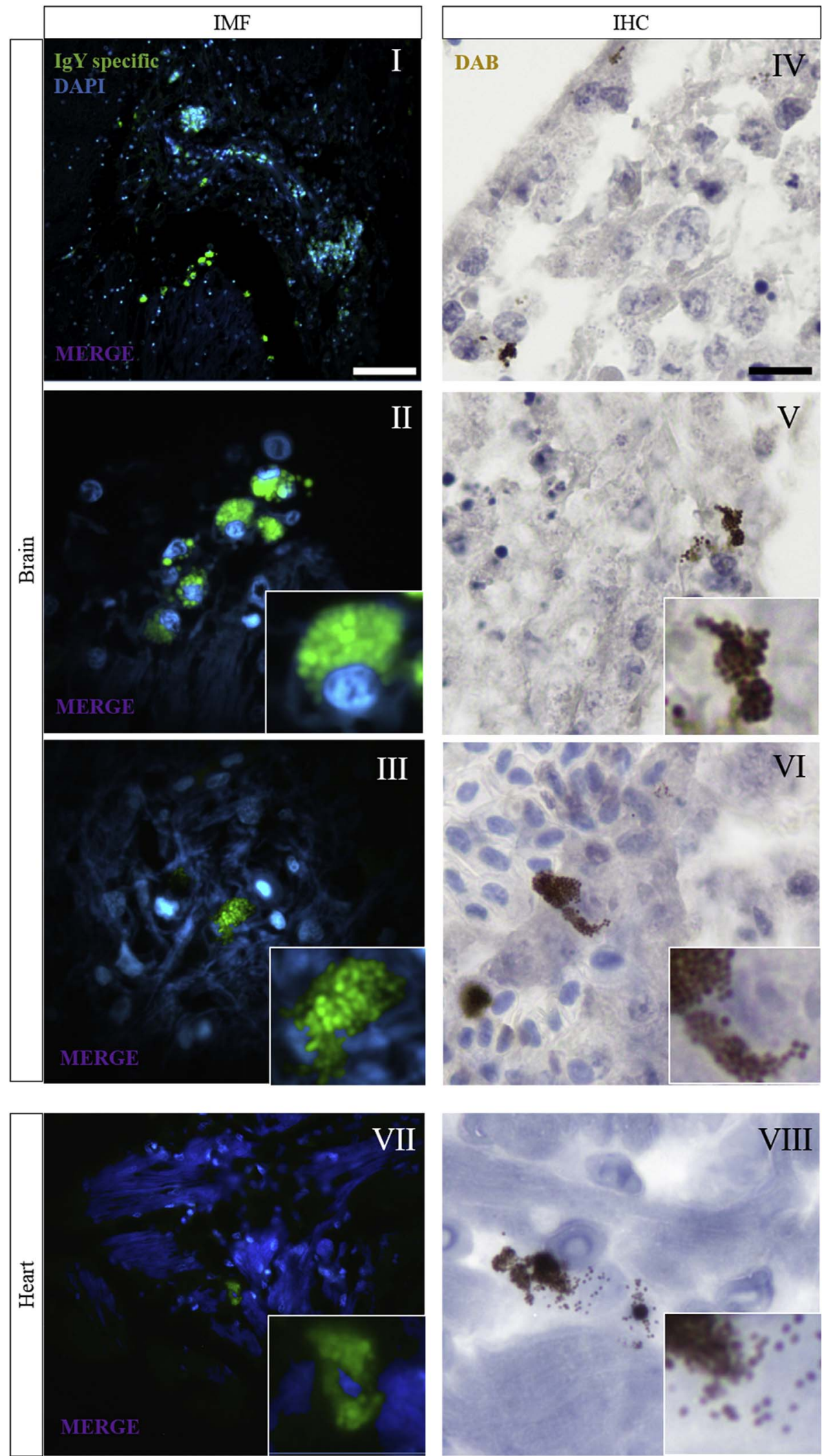

Fig. 6. Potential of anti-Sta IgY for immunolabeling of Streptococcus agalactiae (Sta) bacterial cells using immunofluorescence (IMF) and immunohistochemistry (IHC). Positive in cardiac and cerebral tissue of Oreochromis niloticus (I, IV-V) (large increase); (II-V), intracellular visualization of bacterial cells with coccus morphology internalized in phagocytes in the meninges and endocardium and (III-VI, VII-VIII) cocci in the free phase. Bar: $10 \mu \mathrm{m}$; IHC stain, Harris hematoxylin. 


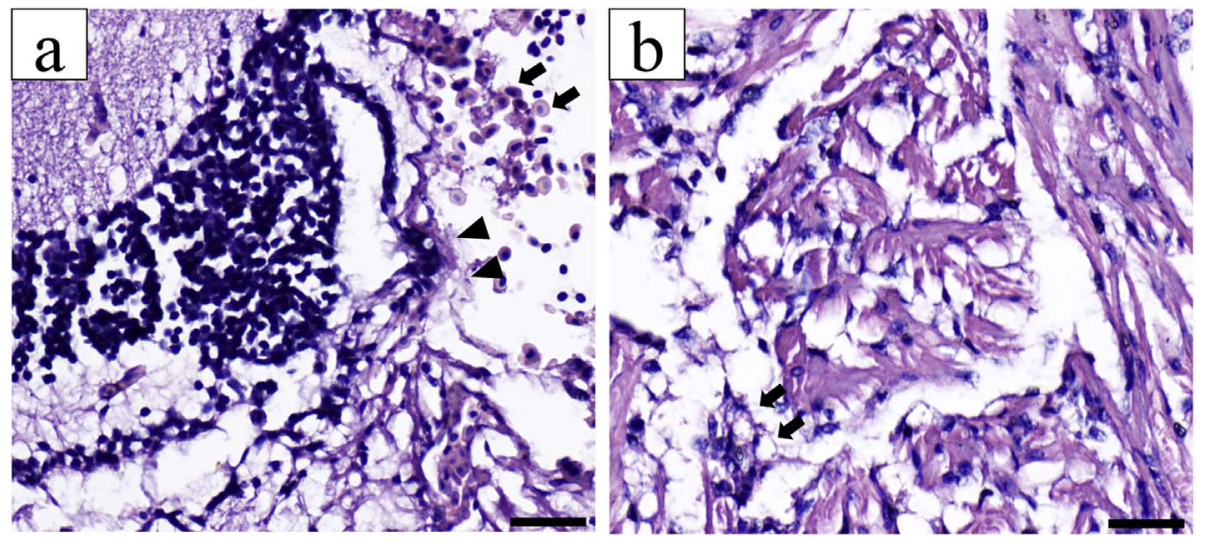

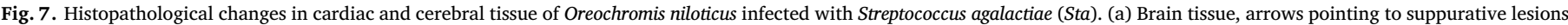
in the meningeal and (b) cardiac tissue with hemorrhagic lesions and leukocyte infiltrates. Bar: $10 \mu$ m; IHC stain, Harris hematoxylin.

for $1 \mathrm{~h}$ with anti-IgY peroxidase (HRP); the absorbance was measured at $640 \mathrm{~nm}$. The values were transformed into an affinity index.

\subsection{IgY purification}

The IgY purification method followed the protocol described by Tong et al. [15]. The yolk was separated, precipitated with pectin (Sigma-Aldrich Corp., St. Louis, MO, USA), dialyzed and stored at $-20^{\circ} \mathrm{C}$ until use.

\subsection{SDS-PAGE}

Dissociative electrophoresis was performed according to Laemmli [16], and $7.9 \mu \mathrm{g}$ of the bacterial fractions and $80 \mu \mathrm{g}$ of purified IgY extract were loaded onto a 9.0\% SDS-polyacrylamide gel in TA buffer at $100 \mathrm{~V}$. The gels were fixed and stained with Coomassie brilliant blue $\mathrm{R}$ $0.25 \%$ (Sigma-Aldrich, St. Louis, MO, USA) and scanned and analyzed with Image Lab software (Bio-Rad, Hercules, CA, USA).

\subsection{Western blotting}

The proteins present in the above gel were transferred to a nitrocellulose membrane (Bio-Rad, Hercules, CA, USA) under constant voltage $(90 \mathrm{~V})$ at $4{ }^{\circ} \mathrm{C}$ for $1 \mathrm{~h}$. The membrane was then incubated with PBS-5\% skim milk at room temperature for $1 \mathrm{~h}$ with continuous shaking, washed, and incubated for $1 \mathrm{~h}$ with anti-Sta IgY solution $(1 \mathrm{mg} / \mathrm{mL})$ diluted at 1:2000. It was subsequently washed with PBSTween and the anti-IgY peroxidase conjugate (diluted 1:2000, added and incubated for $1 \mathrm{~h}$ at room temperature). The reaction was revealed with diaminobenzidine (DAB) substrate (Dako, Carpinteria, CA, USA) and stopped with deionized distilled water, and the membranes were scanned and analyzed with Image Lab software (Bio-Rad, Hercules, CA, USA).

\subsection{Sensitivity test}

Membrane proteins and CPs at concentrations of 5, 10, 15 and $20 \mu \mathrm{g} / \mathrm{mL}$ were adsorbed onto the 96-well plate in a volume of $100 \mu \mathrm{L} /$ well $(\mathrm{n}=3)$ and incubated overnight at $4{ }^{\circ} \mathrm{C}$. After washing and blocking as described in section 2.3.1., the specific IgY was diluted to the same concentrations as the antigen. Detection, staining, blocking and reading of the reaction were as described in section 2.3.1.

\subsection{IgY conjugation with fluorescein isothiocyanate (FITC)}

Specific and non-specific IgY were conjugated with FITC (SigmaAldrich Corp., St. Louis, MO USA) following the manufacturer's recommendations. Thus, a $1 \mathrm{mg} / \mathrm{mL}$ solution of FITC was prepared, and $50 \mu \mathrm{L}$ was added to a $1 \mathrm{mg} / \mathrm{mL}$ solution of IgY diluted in PBS, $\mathrm{pH} 7.4$, and allowed to rotate for $4 \mathrm{~h}$ at $4{ }^{\circ} \mathrm{C}$. The solution was then saturated with $1 \%$ bovine serum albumin (Sigma-Aldrich Corp., St. Louis, MO, USA), and the reaction was blocked with $25 \mathrm{mM}$ ammonium nitrate solution $\left(\mathrm{NH}_{4}\right)$. Xylene cyanol was added, and the solution was filtered through a Sephadex G-100 resin column (Sigma-Aldrich Corp., St. Louis, MO, USA).

\subsection{Experimental infection and biological sample collection}

Nile tilapia $(90.5 \pm 7 \mathrm{~g}$ ) were anesthetized by immersion in benzocaine solution (Sigma-Aldrich Laboratory, Steinheim, Germany) $(1: 20,000 \mathrm{v} / \mathrm{v})$ diluted in $98 \%$ ethanol $(0.1 \mathrm{~g} / \mathrm{mL})$ and challenged with a pre-determined lethal dose $50\left(2.0 \times 10^{5} \mathrm{CFU} / \mathrm{mL}\right)$ of live Sta strains following the recommendations of Wedemeyer [17]. The fish that showed signs indicative of the disease were euthanized by immersion in benzocaine $(1: 500 \mathrm{v} / \mathrm{v})$, and the collected brain and cardiac tissue were fixed in $10 \%$ buffered formalin, processed in paraffin, sectioned into $3-5-\mu \mathrm{m}$-thick cuts, and mounted on slides for use.

\subsection{Immunofluorescence and immunohistochemistry}

The direct IMF method was carried out as described by Robertson et al. [18]. The tissue was deparaffinized and hydrated, and the antigenic recovery was made in moist heat in citrate buffer for $15 \mathrm{~min}$. Blocking of endogenous peroxidase was achieved using a commercial solution (Dako Dual Endogenous; Dako, Carpinteria, CA, USA), and nonspecific sites were blocked with Dako Protein Block Serum-Free (Dako, Carpinteria, CA, USA). The heart and brain slides were then incubated with specific IgY and the non-specific IgY at 1:1000 dilutions. Both were conjugated to FITC and incubated overnight in a dark, moist chamber at $4^{\circ} \mathrm{C}$. The slide was washed, the core was labeled with $4^{\prime}, 6$ diamidino-2-phenylindole dihydrochloride (DAPI; Sigma-Aldrich Corp., St. Louis, MO, USA), and the cut was mounted with Fluoromount for fluorescence microscope analysis (Olympus BX56 series; Olympus Life Science, Center Valley, PA, USA). Indirect IHC was performed following the method of Marin de Mateo [19]. Deparaffinization, antigen retrieval and blocking were carried out by the methodology described for IMF. After blocking and washing, the slide was incubated with the specific IgY, and a duplicate was incubated with non-specific IgY at the 1:1000 dilution overnight at $4{ }^{\circ} \mathrm{C}$. Then, the peroxidase-bound anti-IgY rabbit IgG antibody (Sigma-Aldrich Corp., St. Louis, MO, USA) at a 1:2000 dilution was incubated for $2 \mathrm{~h}$, and the reaction was revealed with DAB (Dako, Carpinteria, CA, USA). The slides were mounted and analyzed by light microscopy, and images were captured by Olympus Stream Capture software (Olympus Life Science, Center Valley, PA, USA). 


\subsection{Statistical analysis}

The data were analyzed by ANOVA and Tukey's test at a significance level of $5 \%$ [20].

\section{Results}

\subsection{Characterization of anti-sta $\operatorname{Ig} Y$}

The production of anti-Sta IgY in bird serum started on day 15 after the first dose of the antigen, and the response pattern was similar for PMs e PC de Sta. There were increases in antibody titers on the 60th day after the 2nd dose of the antigen and on the 120th day after the 3rd dose. The increase in the IgY affinity index was progressive for MPs and CPs and was significant on the 150th day relative to the 15th, 30th, 60th, and 90th days (Fig. 1).

\subsection{Immunogenic profile of bacterial proteins}

The SDS-PAGE gel allowed the two protein fractions (MPs and CPs) to be distinguished, demonstrating the efficiency of the method for separating these proteins. Individual assessment of IgY specificity for the two fractions by Western blotting revealed several immunolabeled proteins-eight for MPs and 10 for CPs-indicating the multi-specific potential of IgY (Fig. 2).

\subsection{IgY purification and characterization}

The pectin precipitation purification method was effective; the SDSPAGE gel of the purified yolk extract showed a 20-kDa band for the light chain (Fab) and a second 75-kDa band for the heavy chain (Fc). The Fc-positive immunolabeling also demonstrated the presence of IgY in the purified extract (Fig. 3).

\subsection{Potential for in vitro sensitivity of $\operatorname{Ig} Y$}

The sensitivity of IgY was tested by ELISA (Fig. 4), and a concentration of $5 \mu \mathrm{g} / \mathrm{mL}$ of specific IgY was effective for detecting 5,10 , 15 and $20 \mu \mathrm{g} / \mathrm{mL}$ of both the Sta MPs and CPs bacterial fractions $(\mathrm{p}<0.05)$. Non-specific IgY did not show significant reactivity when compared to specific IgY. The detection curve increased exponentially and increased relative to the increase in the specific IgY concentration. However, the equivalence zone was observed at a specific IgY concentration of $15 \mu \mathrm{g} / \mathrm{mL}$, while a $20 \mu \mathrm{g} / \mathrm{mL}$ concentration appears to have saturated the antigen-binding sites.

\subsection{Immunohistochemistry and histopathology}

Anti-Sta IgY was efficacious in the detection of intact cocci in Sta culture (Fig. 5), diffuse and phagocyte-internalized in cardiac and cerebral tissue (Fig. 6). The detection sensitivity was similar for both IMF and IHC. In cardiac tissue, immunolabeled cocci were associated with hemorrhagic lesions in the cardiac fibers with the presence of leukocyte infiltrate. In nerve tissue, Sta was associated with suppurative meningitis, which was accompanied by intense inflammation, as shown in the histopathological analysis (Fig. 7).

\section{Discussion}

Several studies have provided evidence for the effectiveness of IgY, which is extracted from egg yolks of laying hens, in the diagnosis and treatment of bacterial infections by Streptococcus mutans [21], Salmonella sp. [22], Yersinia sp. [23], Staphylococcus sp. [24]. and Helicobacter pylori [25], and infections by parasites such as Trichinella spiralis [26] and Schistosoma japonicum [27]. In addition, IgY has been shown to be effective in the diagnosis of tropical diseases such as dengue [28], in the detection of neoplastic cells from human mammary tumors [29,30] and when applied as serotherapy for snake poisoning [31] and as an agent to block bacterial toxins [32].

Therefore, in the present study, we produced a polyclonal IgY by immunizing laying hens with Sta bacterial proteins isolated from tilapia. The humoral immune response of the birds, with only three doses at a concentration of $200 \mu \mathrm{g} / \mathrm{mL}$ each, produced specific IgY for the two bacterial fractions from day 15 , and the antibody titers were constant during the 150 days of the immunization protocol. This enabled the acquisition of large amounts of specific antibodies. In this work, the IgY purification from egg yolk has a low production cost and does not involve bleeding or sacrifice of the bird, as in the production of poly/ monoclonal IgG in mammals [33]. Because eggs contain $100 \mathrm{mg}$ of antibodies in the yolk, on average, and laying hens produce on average of 20 eggs per month, 30 days of IgY production can easily reach values greater than $2 \mathrm{~g}$ per bird, making it economically feasible to use hens for antibody production [34].

In addition, progressive affinity/avidity maturation and the multispecific potential of specific IgY observed in the ELISA and Western blot assay, respectively, demonstrate the efficacy of the immunization method and the ability of the humoral response of the bird to recognize distinct antigenic epitopes between the two bacterial fractions. Another relevant fact is that the method for inactivating Sta by ultrasound preserved the structural and chemical integrity of the bacterial proteins, neutralizing the pathogen by rupture without altering its structure by physical denaturation, heat, or chemical inactivation by aldehydes [35]. Similarly, ultracentrifugation maintained the structural and chemical integrity of the proteins during the separation process [36]. This allowed the recognition of the antigenic epitopes in their native form, producing antibodies of high affinity and avidity, thus increasing the sensitivity of detection of the pathogen. This was demonstrated by the sensitivity test, which suggests a possible application of anti-Sta IgY in the detection of bacteria and their bacterial products, such as exo/endotoxins in biological fluids such as serum, tears, cerebrospinal fluid and other bodily secretions. In fact, preliminary results obtained in our laboratory are based on this application (unpublished data).

The IgY of birds is intrinsically biochemically divergent from mammalian IgG [37]. Due to the phylogenetic distance between the vertebrates, the constant fraction (Fc) of IgY does not have a binding affinity for the C1q molecule of the complement system and the rheumatoid factors present in biological samples of heterologous species, reducing the false-positive reactions for immunological tests [38]. In addition, the heritability of specificity genes, derived from Jurassic ancestors, enables $\operatorname{IgY}$ to recognize antigenic epitopes present in mammals and other phylogenetically distinct species with equal or greater affinity than IgG produced in mammals [33].

In this study, the IgY produced was sensitive enough to detect Sta by direct IMF and indirect IHC in pure colonies and in bacterial cells processed in cardiac and brain tissue. This allowed the distinction of the extra/intracellular location of $S$. agalactiae in host tissue, allowing observation of the two stages of the pathogen's infectious cycle. Another important factor is that the detection sensitivity was similar for both tests in paraffinized tissue. In addition, the ability of the specific IgY to detect the pathogen in paraffin-embedded tissue allows the sample to be fixed and embedded in paraffin, preserving the structural morphology of the tissue as well as the antigenic epitopes and, by confluence, the reliability of the results. This validated the use of IgY for the diagnosis and pathophysiological study of Sta infections in Nile tilapia, as well as the use of this species as a pathophysiological model for this disease and its application in veterinary and human neonatal medicine.

\section{Ethics statement}

All handling of fish an avian was, conducted in accordance with the National Council for Control of Animal Experimentation (CONCEA), 
approved by the ethics council number: 17209/15.

\section{Acknowledgments}

This work was supported financially by, National Council for Scientific and Technological Development (CNPq), process number: 429245/2016-5, and process number 140505/2016-4.

\section{References}

[1] G.F. Mian, D.T. Godoy, C.A.G. Leal, T.Y. Yuhara, G.M. Costa, Aspects of the natural history and virulence of $S$. agalactiae infection in Nile tilapia, Vet. Microbiol. 136 (2009) 180-183.

[2] M. Imperi, M. Pataracchia, G. Alfarone, L. Baldassarri, G. Orefici, R. Creti, A multiplex PCR assay for the direct identification of the capsular type (Ia to IX) of Streptococcus agalactiae, J. Microbiol. Meth. 80 (2010) 212-214.

[3] S. Delannoy, L. Beutin, P. Fach, Discrimination of enter hemorrhagic Escherichia coli (EHEC) from non-EHEC strains based on detection of various combinations of type III effector genes, J. Clin. Microbiol. 51 (2013) 3257-3262.

[4] K.M. Edmond, C. Kortsalioudaki, S. Scott, S.J. Schrag, A.K. Zaidi, S. Cousens, P.T. Heath, Group B streptococcal disease in infants aged younger than 3 months: systematic review and meta-analysis, Lancet 379 (2012) 547-556.

[5] Y.O. Asencios, F.B. Sánchez, H.B. Mendizábal, K.H. Pusari, H.O. Alfonso, A.M. Sayán, M.A.P. Figueiredo, W.G. Manrique, M.A. de Andrade Belo, N.S. Chaupe, First report of Streptococcus agalactiae isolated from Oreochromis niloticus in Piura, Peru: molecular identification and histopathological lesions, Aquac. Rep 4 (2016) 74-79.

[6] P. Lemire, M. Houde, M. Segura, Encapsulated group B Streptococcus modulates dendritic cell functions via lipid rafts and clathrin-mediated endocytosis, Cell Microbiol. 14 (2012) 1707-1719.

[7] J.D. Cherry, J.A. Olschowka, M.K. O'Banion, Neuro-inflammation and M2 microglia: the good, the bad, and the inflamed, J. Neuroinflammation 11 (2014) 98.

[8] C. Rodkhum, P. Kayansamruaj, N. Pirarat, J. Wongtawatchai, Duplex PCR for simultaneous and unambiguous detection of Streptococcus iniae and Streptococcus agalactiae associated with streptococcosis of cultured tilapia in Thailand, J. Vet. Med. 42 (2012) 153-158.

[9] X. Gao, X. Zhang, J. Sun, X. Du, X. Li, Y. Zhang, L. Lin, Passive protection effect of anti-Vibrio anguillarum IgY-encapsulated feed on half-smooth tongue sole (Cynoglossus semilaevi) against V. anguillarum, Fish Shellfish Immunol. 56 (2016) 483-488.

[10] R. Wu, H. Wu, A molecular chaperone mediates a two-protein enzyme complex and glycosylation of serine-rich streptococcal adhesins, J. Biol. Chem. 286 (2011) 34923-34931.

[11] Y. Lu, J. Liu, L. Jin, X. Li, Y. Zhen, H. Xue, J. You, Y. Xu, Passive protection of shrimp against white spot syndrome virus (WSSV) using specific antibody from egg yolk of chickens immunized with inactivated virus or a WSSV-DNA vaccine, Fish Shellfish Immunol. 25 (2008) 604-610.

[12] B.R. Berridgea, H. Bercovierb, P.F. Frelier, Streptococcus agalactiae and Streptococcus difficile 16S-23S intergenic rDNA: genetic homogeneity and species-specific PCR, Vet. Microbiol. 78 (2001) 165-173.

[13] K.A.A. El-Razika, K.A. Abdelrahmanb, Y.F. Ahmeda, A.M. Gomaac, H.A. Eldebakya, Direct identification of major pathogens of the bubaline subclinical mastitis in Egypt using PCR, J. Am. Sci. 6 (2010) 652-660.

[14] V.S. Sato, R.F. Galdiano, G.R. Rodrigues, E.G. Lemos, J.M. Pizauro, Kinetic characterization of a novel acid ectophosphatase from Enterobacter asburiae, J. Microbiol. 54 (2016) 106-113.

[15] C. Tong, F. Geng, Z. He, Z. Cai, M. Ma, A simple method for isolating chicken egg yolk immunoglobulin using effective delipidation solution and ammonium sulfate, Poultry Sci. 94 (2015) 104-110.

[16] U.K. Laemmli, Cleavage of structural proteins during the assembly of the head of bacteriophage T4, Nature 227 (1970) 680-685.

[17] G. Wedemeyer, Stress of anesthesia with MS-222 and benzocaine in rainbow trout
(Salmo gairdneri), J. Fish. Res. Board Can. 27 (1970) 909-914.

[18] D. Robertson, K. Savage, J.S. Reis-Filho, C.M. Isacke, Multiple immunofluores-cence labelling of formalin-fixed paraffin-embedded (FFPE) tissue, BMC Cell Biol. 9 (2008) 1-10.

[19] M. Marin de Mateo, G. Bovo, M. Comuzzi, A. Adams, Lectin histochemical studies on Sphaerospora sp. (Myxozoa) from Italian brown trout, Salmo trutta L, J. Fish. Dis. 20 (1997) 51-58.

[20] G.W. Snedecor, W.G. Cochran, Statistical Methods, Iowa State University Press, Ames, 1974.

[21] H. Hatta, K. Mabe, T. Yamamoto, M.A. Guiterrez, T. Miyazaki, Prevention of fish disease using egg yolk antibody, in: J.S. Sim, S. Nakai (Eds.), Egg Uses and Processing Technologies, CAB International, Wallingford, 1994, pp. 241-249.

[22] H. Yokoyama, R.C. Peralta, K. Umeda, T. Hashi, F.C. Icatlo Jr., M. Kuroki, Y. Ikemori, Y. Kodama, Prevention of fatal salmonellosis in neonatal calves, using orally administered chicken egg yolk Salmonella-especific antibodies, Am. J. Vet 59 (1998) 416-420.

[23] S.B. Lee, Y. Mine, R.M. Stevenson, Effects of hen egg yolk immunoglobulin in passive protection of rainbow trout against Yersinia ruckeri, J. Agric. Food Chem. 48 (2000) 110-115.

[24] R.D. LeClaire, Protection against bacterial superantigen staphylococcal enterotoxin B by passive vaccination, Infect. Immun. 70 (2002) 2278-2281.

[25] J.H. Shin, S.W. Nam, J.T. Kim, J.B. Yoon, W.G. Bang, I.H. Roe, Identification of immunodominant Helicobacter pylori proteins with reactivity to $H$. pylori-specific egg-yolk immunoglobulin, J. Med. Microbiol. 52 (2003) 217-222.

[26] L.N. Liu, F.J. Jing, J. Cui, G.Y. Fu, Z.Q. Wang, Detection of circulating antigen in serum of mice infected with Trichinella spiralis by an IgY IgM mAb sandwich ELISA, Exp. Parasitol. 33 (2013) 150-155.

[27] J.H. Lei, F. Guan, H. Xu, L. Chen, B.T. Su, Y. Zhou, T. Wang, Y.L. Li, W.Q. Liu, Application of an immunomagnetic bead ELISA based on IgY for detection of circulating antigen in urine of mice infected with Schistosoma japonicum, Vet. Parasitol. 187 (2012) 196-202.

[28] A. Figueiredo, N.C. Vieira, J.F. dos Santos, B.C. Janegitz, S.M. Aoki, P.P. Junior, R.L. Lovato, M.L. Nogueira, V. Zucolotto, F.E. Guimarães, Electrical detection of dengue biomarker using egg yolk immunoglobulin as the biological recognition element, Sci. Rep. (2015) 1-5.

[29] Y. Xiao, X. Gao, Use of IgY antibodies and semiconductor nanocrystal detection in cancer biomarker quantitation, Biomark. Med 4 (2010) 227-239.

[30] R. Grzywa, A. Łupicka-Słowik, M. Walczak, M. Idzi, K. Bobrek, S. Boivin, A. Gaweł, T. Stefaniak, J. Oleksyszyn, M. Sieńczyk, Highly sensitive detection of cancer antigen using novel avian IgY antibodies, ALTEX 31 (2014) 43-52.

[31] Y.H. Zheng, F.R. Ang, C. Ding, L.J. Jin, Y.P. Li, S.X.H. Hu, X.C. Ma, Y.P. Xu, Efficacy of specific IgY for treatment of lipopolysaccharide-induced endotoxemia using a mouse model, J. Appl. Microbiol. 111 (2011) 1524-1532.

[32] F.G. Andrade, S.F. Eto, A.C.N.S. Navarro, D.T.G. Marioto, N.J. Vieira, A.P. Cheirubim, S.P. Ramos, E.J. Venâncio, The production and characterization of anti-bothropic and anti-crotalic IgY antibodies in laying hens: a long term experiment, Toxicon 66 (2013) 18-24.

[33] W. D da Silva, D.V. Tambourgi, IgY: a promising antibody for use in immuno-diagnostic and in immunotherapy, Vet. Immunol. Immunopathol. 135 (2010) $173-180$.

[34] P.A. Chacana, H.R. Terzolo, C.E. Gutiérrez, R. Schade, Tecnología IgY o aplicaciones de los anticuerpos de yema de huevo de gallina, Rev. Med. Vet. (B. Aires) 85 (2004) 179-189.

[35] I. Gulseren, D. Guzey, B.D. Bruce, J. Weiss, Structural and functional changes in ultrasonicated bovine serum albumin solutions, Ultrason. Sonochem. 14 (2007) $173-183$.

[36] S. Muthukumaran, S. Kentish, G. Stevens, E. Sandra, M. Ashokkumar, S.W. Geoffrey, Application of ultrasound in membrane separation processes: a review, Rev. Chem. Eng. 22 (2017) 155-194.

[37] L.S. Munhoz, G.D.A. Vargas, G. Fischer, M. Lima, P.A. Esteves, S.O. Hübner, Avian IgY antibodies: characteristics and applications in immunodiagnostic, Ciência Rural. 44 (2014) 153-160.

[38] W.W. Zhang, The use of gene-specific IgY antibodies for drug target discovery, Drug Discov. Today 8 (2003) 364-371. 